\title{
EFECTOS POLÍTICOS \\ DE LOS COMICIOS DE 1997
}

José Antonio Crespo*

\section{Introducción}

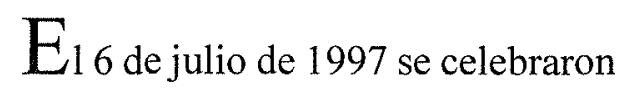
comicios intermedios para renovar el Congreso Federal, asi como seis gubernaturas estatales y, por primera vez desde 1927, se sometió al sufragio ciudadano directo el gobierno de la Capital. El resultado de esta jornada fue la mayor derrota que el PRI haya experimentado en su larga historia como partido hegemónico. Desde luego, en parámetros democráticos pocos partidos considerarían estos resultados como una derrota aplastante, pues el partido oficial consiguió el 40 por ciento de la votación nacional, frente al 26 y el 27 por ciento de sus adversarios más cercanos, respectivamente. Además, logró triunfar en 164 de las 300 diputaciones de mayoría relativa (es decir, en el 55 por ciento de tales distritos). Por ley, todo ello se tradujo en un 48 por ciento de la diputación nacional (239 de 500 escaños, frente a 125 del PRD, 121 del PAN, 8 del Partido Verde Ecologista, y 7 del Partido del Trabajo). También, el partido tricolor ganó en cuatro gubernaturas de las seis que estaban en disputa. Es decir, un holgado triunfo. Su gran derrota, podría decirse, se dio en la capital de la República, cuyo gobierno quedó en manos del PRD, el cual además triunfó en 29 de los treinta distritos federales, y en 38 de los 40 distritos locales. Con todo, en una

* CIDE, México. 


\section{JOSÉ ANTONIO CRESPO}

democracia, los partidos gobernantes suelen perder la capital del país sin que ello represente un fuerte descalabro.

Sin embargo, en el marco de partido hegemónico ${ }^{1}$ ese saldo electoral representa un desastre para él-pues la hegemonía no puede sostenerse con resultados propios de una democracia, ni siquiera con los que arrojan los sistemas de partido dominante democrático (como los que existen en Japón, India y Suecia)- acostumbrado a ganar con holgura y por mucho tiempo la mayoría de los espacios de poder. Esto es, podría decirse que los resultados del 6 de julio han dado fin, al menos en lo esencial, a la tradicional hegemonía priísta. El hecho de que el PRI ya no controle por sí mismo la mayoría absoluta de la Cámara Baja, modifica sustancialmente la dinámica política del país. Desde luego, no se descarta la posibilidad de que por medio de alianzas y artificios (lícitos o ilícitos) el PRI logre preservar el control virtual de la diputación nacional (como intentó hacerlo antes de la instauración de la LVII legislatura). Pero aun en ese caso, la antigua hegemonía ya no podrá ejercitarse de manera automática como antes. Podría pues decirse que la larga época de cambio gradual y superficial que se orientaba hacia la democracia sin llegar a ella, y que por el contrario buscaba retardar

26 tanto como fuera posible la democratización, se ha agotado después de varias décadas de éxito. Los resultados del 6 de julio de 1997 nos han arrojado a una fase de la transición política que seguramente será decisiva en los próximos años para definir si el país se encamina hacia su auténtica democratización por la vía pacífica, o si entra en un terreno de ingobernabilidad, desorden e incluso violencia (riesgo inherente, por definición, en cualquier proceso de transición política). En cualquiera de los dos escenarios, el régimen priísta que emergió de la revolución mexicana de principios de siglo, habrá concluido.

' Por partido hegemónico se entiende aquel que disfruta de un virtual monopolio político y que comparte el escenario con partidos opositores legalmente reconocidos pero sin posibilidades reales de ganar en la lucha por el poder, en virtud de que las condiciones de la contienda electoral garantizan el triunfo del partido hegemónico. Cfr. Sartori, Partidos y sistemas de partidos, 1980, Madrid, Alianza, p. 278-9. 
En este ensayo se sustenta la afirmación de que el característico proceso gatopardista de 'cambiar todo para que todo siga igual', del que el régimen priísta llegó a ser un maestro consagrado, ha llegado a su etapa terminal como consecuencia de los resultados del proceso electoral de 1997. Ello marca el fin de una época, y del régimen de partido hegemónico que prevaleció desde 1929 (aun cuando el PRI como partido no haya desaparecido, y de hecho siga prevaleciendo como el partido mayoritario).

\section{La exitosa liberalización mexicana}

Entre muchas otras cosas, el régimen prísta se ha distinguido por haber aplicado con éxito una estrategia de apertura política destinada a relegar, más que a alcanzar, su propia democratización. Esta peculiar política ha sido denominada dentro de la ciencia política como 'liberalización política', y es típica de diversos autoritarismos que, cuando se percatan de que no podrán continuar con sus rasgos esenciales, emprenden un proceso de apertura limitada o superficial con miras a permitir el desahogo de las tensiones ciudadanas. Con ello es posible prolongarse más en el tiempo sin perder la esencia autoritaria del régimen. ${ }^{2}$ Normalmente, eso ocurre en situaciones de emergencia, cuando la presión ciudadana en contra del régimen autoritario ha cobrado tal intensidad que se hace prácticamente imposible mantenerlo en pie. De ello se percata la élite autoritaria, y opta por abrir nuevos espacios de participación y expresión a la disidencia, con miras a reducir la presión democrática y dar nuevos aires al régimen autoritario.

Sin embargo, suele ocurrir que dicha liberalización, en lugar de paliar las demandas democráticas, las estimula y exacerba, pues la oposi-

${ }^{2}$ Se distingue aquí el autoritarismo de la democracia a partir de la posibilidad de llamar a cuentas a los gobernantes de manera pacífica y legal: esto es posible en una democracia; no lo es en un autoritarismo, por lo cual en este último prevalece como característica la impunidad institucional de la clase gobernante. 
ción y la disidencia utilizan los nuevos espacios otorgados por el régimen, terminando por transformarlo en una democracia o derrocarlo abruptamente. En ese sentido, la liberalización suele ser un preludio no buscado ni planeado de la auténtica democratización. El caso mexicano en esta lógica constituye una excepción; el régimen priísta es en el que la liberalización política ha tenido mayor éxito, al funcionar adecuadamente por décadas, y logrando su objetivo de sustituir una auténtica democratización por una apertura limitada que deje intacta la esencia autoritaria del régimen. ${ }^{3}$ En efecto, la liberalización mexicana ha permitido desahogar las presiones democráticas y el descontento ciudadano haciéndolo perder intensidad en el plazo inmediato. Al mismo tiempo, ha creado la ilusión en la ciudadanía de que tales avances corresponden a una política democrática, aunque ésta se vaya aplicando de manera gradual. ${ }^{4}$

${ }^{3}$ Como lo ha destacado Soledad Loaeza: "La experiencia mexicana contradice la creencia de que la liberalización de un régimen tiene sólo dos posibles resultados: el endurecimiento del autoritarismo o la democratización. Contrariamente a la difundida idea de que la liberalización es una fórmula transicional, la experiencia de México con la liberalización política data de más de veinte años. Su éxito ha significado la cancelación de la democratización, o por lo menos su indefinida posposición." "Political Liberalization an Uncertainty in México", en L. Middlebrook, K. Cook, J. Molinar (eds.), The Politics or Economic Restructuring; State Society Relations and Regime Change in Mexico, 1994, Center of Us-Mexican Studies, UCSD, p. 106.

${ }^{4}$ En palabras de Gabriel Zaid en 1985: "El supremo maquiavelismo del sistema consiste en ceder una y mil veces, ceder aquí y allá, ceder ante unos y ante otros; no antes de tiempo, no más de los necesario, no fácilmente, no gratis, arrebatando muchas veces lo que ya había concedido; nunca ante la' violencia, ni siquiera ante el derecho, pero siempre ante la buena voluntad negociada: siempre alimentando la esperanza de que algo se puede conseguir por las buenas, de que el supremo dador siempre está abierto a escuchar peticiones razonables, respetuosas, de preferencia acompañadas por un gesto de buena voluntad." ("Escenarios sobre el fin del PRI", La economía presidencial, 1987, México, Vuelta, p. 105.) 
Esto ha sido posible gracias a que un proceso de liberalización puede fácilmente ser confundido con uno de democratización, pues las primeras fases de ambos son similares, por lo que la distinción clara entre uno y otro resulta sumamente difícil. Incluso, hay quienes señalan que la única forma de precisar si un determinado proceso de cambio es de corte liberalizador o democratizador, es conociendo el desenlace. ${ }^{5}$ Sin embargo, a veces sí es posible determinar cuándo una reforma concreta puede ubicarse como liberalizadora o democratizadora: la primera se limita a ceder más espacios o cuotas de poder a la oposición y la disidencia, mientras que la segunda otorga capacidad de decisión a instituciones o grupos no controlados por el gobierno. ${ }^{6} \mathrm{En}$ todo caso, queda claro que la liberalización tiene el propósito específico de sustituir y relegar la democratización, independientemente del éxito que tenga en ese objetivo.

El inicio de la liberalización política en México puede ubicarse en al menos dos fechas, que corresponden a dos de las más importantes y sustantivas reformas electorales; en 1964, cuando se abrió a la oposición la posibilidad de contar con diputados de partido a partir de su votación global, y en 1977, cuando además de brindar diversas prerrogativas a los partidos de oposición y abrir los cauces institucionales a los de la izquierda histórica, las diputaciones de partido fueron transformadas en diputaciones de representación proporcional, lo que suponía un mayor número de curules opositoras. En ambos casos, la liberalización mexicana mostró años de éxito en su propósito de rele-

${ }^{5}$ Peter Smith en este sentido, ha enfatizado que: "En términos estrictos resulta difícil (si no es que imposible) saber si se ha dado la democratización, a no ser que se haya logrado la democracia misma; de otra manera, lo que parecería ser una democratización bien podría ser sólo una forma elaborada de liberalizaçión." ("Sobre la democracia y la democratización en América Latina: especulaciones y perspectivas", Foro Internacional, n 113 , julioseptiembre, 1988.)

${ }^{6}$ Adam Przeworski, Democracy and the Market; Political and Economic Reforms in Eastern Europe and Latin America, 1991, Cambridge, U.P., p. 14. 


\section{JOSE ANTONIO CRESPO}

gar el momento de la democratización, dando nuevos aires al peculiar autoritarismo priísta.

El sorprendente éxito de la política de liberalización seguida por el régimen priísta en relación con las intentadas por muchos otros regímenes autoritarios y unipartidistas, exige desde luego un intento de explicación. En primer lugar, tenemos la estructura formal del régimen priísta de tipo democrático, que permite abrir nuevos espacios de participación y expresión sin necesidad de transformaciones institucionales de fondo, sino simplemente a través de la activación parcial de los que están contemplados en la ley. Las instituciones del régimen prísta, aunque fueron adaptadas para conseguir los propósitos propios del autoritarismo (erigir un monopolio de poder y garantizar la impunidad de la élite gobernante) hubieron de ser diseñadas según el patrón democrático para satisfacer sus necesidades básicas de legitimidad política y de reconocimiento internacional (en particular, del gobierno norteamericano).

Los procesos de liberalización normalmente se instrumentan cuando la presión opositora ha llegado a un nivel sumamente desafiante, y por ello la apertura es aprovechada por la disidencia para profundizar

30 la exigencia democrática. Es como una olla de presión que al dejar escapar una fuga, estalla. En cambio, cuando las reformas se aplican en una situación de debilidad opositora, se abre con anticipación un conducto por el cual podrá canalizarse la presión opositora cuando ésta se incremente. No parece casual que precisamente las dos reformas electorales más significativas (aparte de la de 1994, que mostró algunos avances claramente democratizadores) la de 1964 y la de 1977, se realizaron precisamente cuando la oposición daba muestras de excesiva debilidad, e incluso la posibilidad de desmoronarse por completo. ${ }^{7}$

Es cierto que otras reformas se han tomado como una reacción a los golpes recibidos; es decir, no han respondido a un plan preestablecido de largo plazo, y sin embargo, la táctica de abrir el régimen un poco

${ }^{7}$ Cfr. Juan Molinar, "La legitimidad perdida"; Nexos, $n^{\circ} 164$, agosto de 1991. 
para conservar el poder parece haber sido adoptada deliberadamente por la élite gubernamental y transferida de sexenio en sexenio como una fórmula general políticamente muy fructífera. ${ }^{8}$ Así, considerando los buenos resultados de hacer reformas cuando la presión es reducida y la oposición se encuentra debilitada, si nada obliga a realizarlas, habría que preguntar cuál es la motivación para hacer tales reformas. Suena perfectamente comprensible que se ceda terreno ante una presión incontenible, pero parece hasta cierto punto irracional ceder si no hay una fuerza que orille a tomar esas medidas. La explicación se encuentra en las características mismas del régimen hegemónico y sus necesidades inherentes. Por ejemplo, como la formalidad democrática exige la celebración de elecciones competitivas, se hace necesaria-más aún, imprescindible- la presencia en la arena electoral de partidos opositores legalmente registrados. Pero como las elecciones no han sido auténticamente competitivas, entonces hay una contradicción esencial entre la participación electoral de la oposición, en condiciones en que un triunfo es poco menos que imposible, al menos en los niveles superiores del poder. Esa situación llevaría fácilmente a la desmotivación o a la desintegración de la oposición, lo que conlleva el riesgo implícito de que el partido oficial quede en la palestra electoral como un auténtico partido único -si acaso rodeado de partidos sin la menor credibilidad, lo que no hace muy distinta la situación. Así, precisamente cuando los partidos de oposición 'amenazaban' con desaparecer de la arena electoral era cuando sobrevenía una reforma importante, capaz de dar nuevos bríos y estímulos a la oposición sin poner en riesgo la hegemonía del partido oficial. Se trataba pues de reformas auténticamente liberalizadoras, pero aplicadas en condiciones que favorecerían el éxito de sus propósitos inherentes.

${ }^{8}$ Cfr. Loaeza, "Political Liberalization ...", op. cit., p. 109. 
JOSÉ ANTONIO CRESPO

\section{Los límites de la liberalización}

Pese al sorprendente éxito de la estrategia liberalizadora en México, era lógico pensar desde hace años que en algún momento tocaría sus propios límites; las condiciones que hacían posible la prolongación del régimen autoritario tarde o temprano tendrían que modificarse. Por lo cual, la liberalización tendría que cambiar de rumbo y convertirse en una auténtica democratización, o quizás buscaría prolongarse indefinidamente hasta que no pudiera dar más de sí y llegara a un punto en que surgirían fuertes problemas de ingobernabilidad.

El punto a partir del cual varios analistas percibieron que la liberalización política no podría prolongarse con éxito durante muchos años más fue la crisis económica de 1982, que marcó el agotamiento del modelo de desarrollo emprendido desde 1946. Por un lado, la crisis limitaría los recursos económicos con que tradicionalmente se había mantenido funcionando el sofisticado y complejo aparato político, lo que provocaría rupturas en el interior del régimen. Por otro, el costo de la crisis golpearía a sectores ciudadanos otrora identificados con el partido oficial, o simplemente apáticos frente al fenómeno político, que con seguridad se movilizarían en contra del régimen. Por lo mismo -se insistía en esos años- sería prácticamente imposible continuar la liberalización como si nada hubiese pasado. ${ }^{9}$

${ }^{9}$ Por ejemplo, Gabriel Zaid señaló: "Estamos aburridos de escuchar desde hace décadas que el sistema va a tronar, sin que pase nada. Quizás por eso, desde 1968, los presidentes han llegado a límites que antes parecían inconcebibles, como si se hubieran convencido de que el sistema es invulnerable, pateable, irrompible. (...) Sin embargo, es más probable que un sistema truene cuando parece invulnerable y, por lo mismo, a nadie se le ocurre pensar que pueda suceder lo inconcebible. Cuando es tan viejo que ya no corresponde a las nuevas circunstancias. Cuando se ha vuelto un mastodonte lleno de parches, apoyos ortopédicos, interconexiones, bypasses, marcapasos, duplicaciones. Cuando no ha tronado en mucho tiempo. Cuando está 
La única alternativa para dirigir por una vía pacífica y ordenada el cambio político parecía partir de la conciencia por parte de la élite oficial de que las condiciones exigían un giro de rumbo hacia la democracia, que podría ser dirigida desde arriba por la propia élite gubernamental. Ello traería sin duda costos al partido oficial y al régimen en su conjunto, pues no se podría mantener el monopolio hegemónico del PRI, el carro completo electoral, ni las facultades metaconstitucionales de la institución presidencial. Pero a cambio, el PRI tendría tiempo suficiente para adaptarse perfectamente a las nuevas condiciones democráticas, y dentro de ellas podría mantener por varios años más lo esencial del poder, aunque éste fuera en adelante limitado y compartido. De cualquier forma, se trataba de una mejor opción que el derrumbe institucional en medio de la ingobernabilidad e incluso la inestabilidad. ${ }^{10}$

Pero tal decisión exigía que la élite priísta se percatara sin lugar a dudas de que en efecto la nueva situación era ésa, y que ya no habría posibilidades de tener éxito en alargar el autoritarismo a través de la tradicional estrategia de liberalización por mucho tiempo más. Si seguía pensando en las ilimitadas posibilidades de tal estrategia, la élite continuaría sin dar el golpe de timón democrático que más adelante se requería para evitar colusiones políticas y sociales. Desde luego, quienes eso aconsejaban estaban conscientes de la relativa fortaleza del régimen priísta, y sabían que el colapso, en caso de darse, no vendría de un día para otro, como ocurrió en autoritarismos más rígidos y rudimentarios. El desgaste institucional sería gradual pero constante, y de no generarse una nueva institucionalidad democrática se podría caer en un vacío institucional proclive a la ingobernabilidad.

Miguel de la Madrid tuvo tiempo suficiente para iniciar la democratización desde arriba, como algunos le aconsejaron. Pese a la crisis económica, el margen de tiempo con que contaba haría relativamente

sobrecargado y se le exige más, como si no tuviera límites. Cuando lo tratan a patadas." ("Escenarios sobre el fin del PRI", op. cit., p. 109-10.)

${ }^{10} \mathrm{Cfr}$. José Antonio Crespo, "PRI: de la hegemonía revolucionaria a la dominación democrática", Política y Gobierno, n 1, enero-julio de 1994. 
sencillo el viraje, y la legitimidad perdida por el PRI por la propia crisis económica podría ser sustituida -al menos parcialmente-por la legitimidad derivada de propiciar el cambio democrático. Esa empresa sería seguramente premiada por los ciudadanos mismos en las urnas, por más que muchos votos se dirigieran a la oposición. De la Madrid, como paliativo a los esfuerzos económicos que pediría a la población, inauguró su gobierno ofreciendo la democratización integral y aceptó cierta apertura en el ámbito electoral, que se tradujo en importantes triunfos opositores en varias ciudades importantes, particularmente del norte del país. Eso provocó el temor del presidente de que pudiera darse el temido 'efecto dominó' sobre el resto de la República y decidió dar marcha atrás, recurriendo una vez más a la liberalización limitada que quedó concretada en el Código General Electoral de 1987. La elección de Chihuahua de 1986 -en la que el PAN tuvo posibilidades reales de triunfar y se practicó un enorme fraude en favor del PRI- fue una oportunidad desperdiciada para iniciar el cambio democrático y desahogar la tensión ciudadana acumulada a lo largo del sexenio, y así poder aterrizar en unos comicios presidenciales menos tensos.

\section{La estrategia de Salinas de Gortari}

Las turbulentas elecciones de 1988 representaron un claro aviso de que en efecto, el régimen autoritario estaba llegando a sus límites, y de que la liberalización pronto sería incapaz de sacarlo adelante. En ese año el régimen rayó la línea de la inestabilidad. Era de suponer que el nuevo gobierno de Carlos Salinas de Gortari tomara en cuenta ese enorme foco rojo y procediera a dirigir una auténtica democratización. No faltó una oferta en ese sentido, y el reconocimiento del triunfo panista en Baja California en 1989 alimentó esa expectativa en muchos sectores. Pero a los pocos meses, cuando se aprobó la nueva legislación electoral, se vislumbró la verdadera cara de la reforma política salinista: continuar con la liberalización, ciertamente en un grado desconocido, pero sin soltar la capacidad de decisión. Además, la libe- 
ralización tendría un carácter 'selectivo', es decir, amplia para el PAN y muy estrecha para el PRD."

Ello reflejaba que el nuevo gobierno habia hecho una lectura particular de los eventos de 1988: se trataba casi exclusivamente de una reacción a las dificultades económicas que se habían experimentado a lo largo del gobierno de De la Madrid, y a la ausencia de una programa de asistencia social. Para recuperar el voto, y por tanto apuntalar una vez más el régimen priísta, bastaría con mejorar los indicadores macroeconómicos y poner en marcha un vasto programa de promoción social. Si como lo reflejan las encuestas y los estudios de comportamiento electoral en todo el mundo, la prioridad de la ciudadanía es su bienestar económico y social, entonces con las medidas aplicadas por el gobierno de Salinas el voto volvería a sus cauces priístas a nivel federal, pero también en muchos comicios estatales.

En efecto, en el caso de la mayoría de los electores la principal motivación política radica en la promoción de sus intereses más inmediatos; trabajo, salario, educación, servicios, etc. La democracia per se suele ser una idea abstracta, que en sí misma no genera una motivación suficiente para movilizar a los ciudadanos (salvo a unos cuantos convencidos). Por lo general las cosas son a la inversa; los errores y abusos del gobierno, que afectan las condiciones de vida de la población, provocan una movilización que puede minar las bases del autoritarismo y, en ciertas condiciones, abrir el paso a la instauración de la democracia. ${ }^{12}$ Pero si las necesidades básicas de la población son satisfactoriamente atendidas, entonces la movilización pierde razón de ser. En ese sentido, la estrategia de Salinas tenía algún sentido, y podía conseguir sus propósitos al menos de corto plazo. Los comicios federales de 1991 sugirieron que en efecto, la principal preocupación ciu-

${ }^{1}$ Cfr. José Antonio Crespo, Urnas de Pandora; partidos y elecciones en el gobierno de Salinas, 1995, México, Espasa Calpe / Cide, cap. II.

${ }^{12}$ Cfr. José Antonio Crespo, "Democracia, acción ciudadana y vida cotidiana", en Miguel Concha (coord.), Los derechos politicos como derechos humanos, 1994, México, La Jornada/UNAM. 


\section{JOSÉ ANTONIO CRESPO}

dadana se centraba en su situación y oportunidades económicas. El PRI había obtenido más del 60 por ciento de la votación global, y los ciudadanos no respondieron a la convocatoria hecha por los partidos de oposición para protestar por lo que consideraron un fraude no muy visible. Las movilizaciones registradas en Guanajuato y en San Luis Potosí respondían a afrentas más locales y muy profundas hechas por varios gobernadores priístas. Pero incluso en esos estados, las encuestas mostraban acuerdo con el desempeño de Salinas de Gortari.

Para justificar un ritmo más lento en la reforma política, Salinas advirtió que si se hacía la reforma económica de manera simultánea a la política, el país enfrentaría una crisis parecida a la soviética, en la cual se perderían ambas. ${ }^{13}$ En realidad, el problema no sólo era de ritmo sino también del tipo de apertura pues al dejar relativamente marginado al PRD de la reforma, se cerraban los canales institucionales de expresión a diversos sectores que pudieran identificarse con ese partido. Además, al no avanzarse en la construcción de un nuevo marco institucional, cualquier tropiezo económico podría generar una situación de ingobernabilidad, pues no existían las instituciones adecuadas para canalizar el descontento y la decepción resultantes. ${ }^{14}$ Además, no se lograría generar una suficiente credibilidad electoral para garantizar unos comicios presidenciales ordenados, en caso de que se tornaran altamente disputados.

El gobierno no tomó en cuenta esos riesgos pese a las advertencias que en ese sentido hicieron diversos analistas; si 1988 fue conflictivo,

\section{${ }^{13}$ Entrevista en New Perspectives Quarterly, 8, invierno de 1991.}

${ }^{14}$ Es en este sentido que Miguel Ángel Centeno señala: "Aquí radica la principal contradicción en el doble proyecto presidencial de liberalización económica y política. La élite dominante no parece percatarse.la dificultad de ganar votos sin la promesa de beneficios de corto plazo. Se rehusa a reconocer que puede haber una contradicción básica entre la austeridad económica y el éxito electoral. Pedir a la población continuar haciendo sacrificios en aras de una mal definida modernidad es una cosa, solicitarle su voto es otra cosa." (Democracy within reason;" Technocratic Revolution in Mexico, 1994, The Pennsylvania State, U.P., p. 224.) 
1994 podría serlo aún más, no obstante la aparente recuperación económica y electoral del régimen. Ello en virtud del ciclo sexenal que desde hacía años se había desatado, y según el cual cada fin de gobierno terminaba con una crisis mayor que la anterior. La eventualidad de que el final del gobierno de Salinas no escapara a esta tendencia no debía descartarse, y por ello resultaba fundamental preparar el marco político para resistir una posible crisis en ese ámbito o un tropiezo económico. Así, por ejemplo, Gabriel Zaid escribió en diciembre de 1991:

Que el sexenio termine mal es indeseable, por lo cual muchos no quieren ni pensarlo. Pero no está de más considerar esa posibilidad. (...) La deuda externa no se pagó; dejó de preocupar, que es distinto, como en las terapias tranquilizadoras (...) abunda el capital golondrino que, ante un posible viraje negativo, puede irse. (...) Todo puede empezar en 1993, con una bronca interna del PRI, ante la sucesión presidencial. Mientras se define el resultado de la lucha por el poder, los capitales golondrinos salen a buscar resguardo. El déficit comercial dẻja de ser financiable, lo cual obliga a devaluar, lo cual provoca un descontento mayúsculo. (...) Si no hay avances en el nivel real (aceptando, como un mal menor, media docena de gubernaturas de oposición en 1992), el apalancamiento excesivo en las promesas de modernización puede acabar con el milagro. ${ }^{15}$

Y en efecto, al finalizar el sexenio se vio con claridad que la estrategia de liberalización política seguida por Salinas resultó insuficiente pese a que, paradójicamente, se trataba del gobierno que más espacios había cedido a la oposición, tanto en el nivel municipal como en el de gubernatura. Eso demuestra, por un lado, que se requería de una reforma más cualitativa que cuantitativa, y por otro que las condiciones sociales del país ya no soportaban una política de liberalización, y en cambio exigían una auténtica democratización.

15 "Sobregiros de confianza", La Jornada, 26 de diciẹmbre de 1991. 
JOSÉ ANTONIO CRESPO

El cálculo del gobierno de Salinas, según el cual aún había tela liberalizadora de donde cortar, falló. El éxito que mostró durante décadas la estrategia liberalizadora del régimen priísta dificultaba que la élite oficial se percatara de que ya no podría prolongarse por más tiempo, y de que sería imprescindible cambiar drásticamente el rumbo y el ritmo de la reforma política. En el caso mexicano operó una y otra vez el principio según el cual una élite autoritaria persiste en mantener el mando con condiciones económicas difíciles o no. Si la situación es complicada, entonces no puede hacerse la reforma democrática pues resulta muy arriesgado perder el control político, y si la situación no lo es, entonces el cambio es innecesario. Con ello se pierde una magnífica oportunidad de dirigir la reforma cuando la situación económica es favorable y abre un margen mayor de maniobra con cuyas nuevas reglas el grupo en el poder puede beneficiarse.

Ése pudo ser el caso en 1991, cuando la situación económica parecía inmejorable, y después de una marcada recuperación electoral del PRI. Muchos analistas advirtieron también en esta ocasión el riesgo de que el gobierno leyera los resultados electorales de ese año no como una oportunidad para emprender el cambio sino como la restauración del régimen, que por tanto permitía relegar la reforma democrática otros años. Ésta fue, evidentemente, la interpretación que el gobierno hizo de esos comicios, para proceder a restringir todavía más la liberalización aceptando tan sólo el triunfo del PAN en Chihuahua y en Mérida, pero manteniendo una política de 'carro completo' en el resto de la República, sobre todo en Michoacán, donde una elección limpia pudo haber aflojado la tensión política prevaleciente en el ámbito político-electoral. Podría decirse en más de un sentido que Michoacán en 1992 cumplía un papel parecido al que jugó Chihuahua en 1986. Pero el gobierno de Salinas no asimiló la experiencia del sexenio anterior, que aconsejaba abrir el sistema electoral poco antes de los comicios presidenciales para brindarles un ambiente de más calma y dotarlos de credibilidad electoral. De ese modo, la liberalización política practicada por Salinas, habiendo sido quizás la mayór - cuantitativa y cualitativamente- resultó insuficiente para evitar la esperada crisis de fin de 
sexenio, la cual por su magnitud probablemente dañó la espina dorsal del régimen de partido hegemónico.

\section{La reforma electoral y los comicios de 1997}

Los eventos de 1994 (el conflicto chiapaneco, el asesinato de Luis Donaldo Colosio, el riesgo de un fuerte conflicto post-electoral en caso de un resultado cerrado y, finalmente, la devaluación), constituyeron el marco que en el nuevo gobierno de Ernesto Zedillo generó la sensación de que la estabilidad del país no podría sostenerse a partir de la misma estrategia liberalizadora que se había aplicado con éxito. Pese al holgado triunfo del PRI en los comicios de 1994, la situación política de alguna forma exigía un cambio que garantizara la conformidad y el acuerdo de los principales partidos políticos; ello tendría que empezarse por fuerza en la legislación electoral, que define las reglas para dirimir la lucha por el poder.

Así, el presidente Zedillo anunció su reconocimiento de que era el momento de abandonar un sistema electoral semicompetitivo, para pasar 'definitivamente' a uno claramente competitivo, fuera cual fuera el resultado. Desde luego, en caso de cumplirse tal oferta significaría que el rumbo de la liberalización política sería modificado, para aproximarlo de manera más clara a un terreno democratizador. Ello no significa, como muchos priístas suelen interpretar, que el poder haya de ser cedido a la oposición; simplemente significa que éste se pondrá en juego en condiciones de mayor equidad, imparcialidad y transparencia, lo que no cierra las posibilidades de un triunfo priísta; simplemente deja de garantizarlas.

Como lo expresó en su primer Informe de gobierno, Zedillo permitió la instrumentación de una reforma que supusiera un salto cualitativo hacia la competitividad:

De tiempo atrás el Gobierno federạl está preparado para discutir con seriedad las transformaciones que el exige el pleno 
JOSÉ ANTONIO CRESPO

desarrollo democrático de México. Un elemento primordial es una reforma electoral que sea definitiva, no por negar futuras adecuaciones, sino por terminar ya con la insatisfacción y las controversias sobre lo esencial. Esta reforma debe garantizar autonomía plena de los órganos electorales y condiciones de equidad en la competencia.

Durante ese mismo evento surgió también el compromiso de los cuatro partidos con representación en el Congreso Federal de hacer su mejor esfuerzo por buscar una reforma de manera consensada, sobre la base de que tal acuerdo, además de empujar de manera decisiva a la democracia electoral, podría servir como punto de apoyo para continuar con una reforma integral del Estado. El hecho de llamar 'definitiva' a la reforma y de expresarla en términos de un cambio cualitativo, implica un reconocimiento oficial de que toda la anterior evolución electoral había rayado en la superficie de la democracia y la competitividad, sin cruzar el umbral (es decir, que había formado parte sustancial de una estrategia de liberalización política). Un criterio fundamental para evaluar un sistema electoral en su conjunto -independientemente

de cuál sea su normatividad específica- es su eficacia para lograr un consenso entre los participantes -incluyendo, por supuesto, a los perdedores- sobre la veracidad del veredicto oficial. Desde luego, el tipo de normatividad con que se cuente está relacionado estrechamente con la posibilidad de lograr ese consenso, pero no lo garantiza. De ahí que la reforma electoral 'definitiva' haya sido también proyectada para terminar con los constantes y reiterados conflictos post-electorales. $\mathrm{Si}$ un sistema electoral no puede evitar esas persistentes fricciones y desacuerdos, podrá ser todo lo 'democrática' que se quiera pero será ineficaz en sus propósitos específicos (garantizar una pugna pacífica y civilizada por el poder). A eso se refería también Zedillo cuando, al firmarse el Acuerdo Político Nacional (o "Acuerdo de Los Pinos") en enero de 1995, destacó: 
La reforma del poder que México reclama debe erradicar suspicacias y recriminaciones que empañan los procesos electorales. (...) La democracia electoral debe garantizar la competencia equitativa y transparente, para que cada elección municipal, estatal y federal nos deje satisfechos, cualesquiera que sean sus resultados.

Una legislación equitativa favorece el reconocimiento del veredicto electoral por parte de los perdedores formales -con lo que se evitan los desgastantes y riesgosos conflictos post-electorales-si bien es cierto que no todo depende de una buena legislación -es decir, una que permita comicios competitivos. Tienen en ese sentido alguna razón los partidos de oposición cuando además de leyes adecuadas exigen hechos por parte del gobierno y su partido -traducidos como reconocimiento de los triunfos opositores- que infundan credibilidad en el sistema electoral, tanto a nivel nacional como estatal. De hecho, la aceptación de un veredicto por todos los contendientes no es tanto una cuestión de 'honestidad cívica' o 'cultura democrática', sino producto de un cierto equilibrio político que orilla a los participantes a buscar un acuerdo para resolver los conflictos de interés y la lucha por el poder de manera pacífica y civilizada (evitando los costos de una confrontación). Cuando una conflagración civil resulta costosa para todos, y el riesgo de que ocurra es real, las partes tienden a buscar un acuerdo por conveniencia propia (aunque nada garantice que lo consigan).

Así lo declararon los partidos políticos, si bien era de esperar que durante la negociación concreta cada uno de ellos pugnara por orientar las nuevas reglas electorales en función de sus necesidades y características propias. Eso es lo usual; el problema surge cuando por esa razón no se logra un acuerdo satisfactorio para todos. En lo fundamental, y después de haber cedido cada actor una parte de sus demandas, se logró un consenso - un poco forzado y jaloneado- para la aprobación constitucional de la nueva normatividad electoral. Sin embargo, al aterrizar en la ley secundaria, el Código Federal de Instituciones y Procedimientos Electorales (COFIPE), surgieron nuevas diferencias. En 
JOSÉ ANTONIO CRESPO

particular, el PRI no quiso arriesgar que el monto del ahora predominante financiamiento público a los partidos fuera determinado por las autoridades electorales, según quedó estipulado en la Constitución, pues se corría el riesgo de que se aprobara una suma insuficiente para que el partido oficial lograra su propósito fundamental: preservar la mayoría absoluta de la Cámara Baja.

Por este motivo la bancada priísta introdujo una cláusula transitoria en la ley electoral que arrebataba al Instituto Federal Electoral su facultad constitucional para determinar el monto del financiamiento partidista, y por una sola ocasión (es decir, durante los comicios de 1997) lo dejaba en manos del propio Congreso. La oposición se opuso a tal cláusula al considerarla (correctamente) como anticonstitucional (pues contradecía abiertamente lo establecido por la Carta Magna). Además, el monto que el PRI quería determinar para los partidos (más de dos mil millones de pesos) pareció excesivo a la oposición. De modo que la aprobación del nuevo COFIPE reformado se realizó única y exclusivamente por la bancada priísta, rompiendo el espíritu de consenso que había prevalecido durante todo el proceso de la reforma electoral. La justificación oficial para determinar ese monto (similar al gastado en Japón en 1996, país considerado como uno de los que más recursos destinan a sus campañas) fue que con ello se evitaría la introducción de dinero 'sucio' (es decir, del narcotráfico) en las campañas. Sin embargo, extraoficialmente algunos dirigentes priístas señalaron que la verdadera causa era que sin ese dinero, el PRI no podría ganar la mayoría absoluta del Congreso a la que aspiraba (lo cual de cualquier forma ocurrió).

Ante las impugnaciones que en esa instancia hicieron el PRD y el PAN, y con la advertencia del presidente Zedillo de que en ese punto sería intransigente, como no lo había sido en ninguno otro, la Suprema Corte de Justicia falló en favor del PRI. Pero los esfuerzos del PRI por garantizar su mayoría absoluta no quedaron ahí. A lo largo del proceso electoral también se registraron los siguientes hechos:

1) EI PRI fue el único partido que sé opuso una resolución del IFE para dificultar la práctica de compra e inducción del voto, impugnán- 
dolas ante el Tribunal Electoral, el cual a su vez falló en favor del partido tricolor, dejando sin validez tal medida. Esto no hace sino sugerir la disposición del tricolor a seguir incurriendo en esa añeja pero eficaz práctica (aprovechando la inherente dificultad para detectarla, documentarla y penalizarla).

2) Hubo un intento de la diputación priísta de prohibir en la ley electoral que las organizaciones de observadores recibieran fondos extranjeros, que básicamente se iban a concentrar en evitar el fraude preelectoral. Esta decisión resultó obstruida en razón de que la Constitución prohibe que se modifique la ley electoral noventa días antes de los comicios. Pero la sola intención sugiere que el PRI tiene algo que esconder en este ámbito, pues nada ganaría con despertar sospechas sin que en efecto hubiese algo que ocultar. Por el contrario, cuando el PRI ha tenido confianza en sus propios triunfos ha promovido toda la vigilancia posible (como ocurrió en 1994), precisamente para imprimirles mayor credibilidad.

3) La Cancillería mexicana logró obstruir el financiamiento externo a los proyectos de observación preelectoral, de modo que, por ejemplo, la Academia Mexicana de Derechos Humanos finalmente no recibió ni un centavo de lo que le ofreció la Unión Europea, pese a que esa decisión dependía del IFE y que éste dio su visto bueno a dichos recursos. En este sentido, cabe llamar la atención sobre la contradicción en que ha caído nuestro pais, pues el IFE preside la Unión Interamericana de Organismos Electorales que en su III Conferencia, realizada en México en 1996, llegó al acuerdo de promover fondos internacionales para la observación electoral; al tiempo que nuestra cancilleria ha hecho precisamente lo contrario, con éxito. Además, con ello la Secretaría de Relaciones Exteriores ha vulnerado en la práctica la autoridad y las facultades legales que la Constitución otorga al IFE, minando en consecuencia la eficacia de dicha institución, vital para generar la urgente credibilidad electoral.

4) La Secretaría de Hacienda se encargó de desalentar el financiamiento privado a la observación electoral al no hacerlo deducible de impuestos, lo cual se tradujo en que los posibles donantes retiraran su 
oferta de fomentar la observación con recursos nacionales. Así, el Fondo de estímulo a dicha actividad que se formó a instancias del IFE, percibió 12 millones de pesos del erario público, cuando se había establecido que contaría con el triple.

Todo ello representaba una jugada riesgosa para el PRI, pues si en efecto hubiera alcanzado el umbral del 42.2 por ciento que la nueva ley exige para lograr la mayoría absoluta en la Cámara Baja, de inmediato se hubiera suscitado la sospecha opositora de que parte de esa votación habría sido producto de manejos ilícitos, pues el Gobierno y su partido habían hecho todo lo posible por ocultar sus operativos (registrados por múltiples organizaciones de observación electoral) de compra y coacción del voto, y desvío de fondos públicos en su favor. El resultado, aunque hubiera sido satisfactorio para el PRI, habría echado por tierra el objetivo de la reforma electoral 'definitiva': conseguir la conformidad con el veredicto por parte de todos los contendientes. No se trata, desde luego, de asumir la posición (ampliamente difundida entre disidentes y opositores al régimen) de que sólo la derrota del PRI hace creíbles los comicios, pero si el partido oficial dio muestras de conductas sospechosas, un triunfo ganado por un estrecho margen 44. automáticamente se vuelve motivo de duda. Así, un triunfo del PRI se convierte en creíble bajo dos condiciones A) que sea muy holgado (como los de 1991 y 1994), o B) que incluso no siéndolo se realice en condiciones que no dejen lugar a dudas sobre su limpieza, pues con un resultado cerrado cualquier irregularidad (incluso la más pequeña) puede ser decisiva para alterar el resultado.

Así, justamente porque el PRI no alcanzó la mayoría absoluta de la Cámara Baja el veredicto fue aceptado como válido por los opositores, y en virtud de que, por las nuevas condiciones electorales, el PRI no pudo remontar ilícitamente ese resultado se vio obligado también a reconocerlo. El consenso electoral buscado por la reforma electoral zedillista en lo fundamental se logró por la relativa derrota del PRI (en la elección federal, si bien quedaron impugnados los casos de Campeche y Colima). Esto queda pendiente para los próximos comicios locales, sobre todo porque la confiabilidad de los comicios no debe depender 
del resultado sino de la limpieza y equidad del proceso. Sólo así se podría conciliar un triunfo del PRI (sobre todo uno apretado) con la aceptación plena del veredicto y el reconocimiento de la elección como suficientemente competitiva y limpia. De todas maneras, el hecho de que el PRI haya perdido la mayoría absoluta de la Cámara Baja abre nuevas y promisorias perspectivas a la democratización mexicana, por las siguientes razones:

A) Por un lado, abriría una enorme válvula de escape para desahogar el acumulado descontento de gran parte de la ciudadanía cuyo nivel de vida se ha visto gravemente afectado, con lo cual las tensiones se reducirían, facilitando el tránsito democrático a la democracia.

B) En segundo lugar, los disidentes al régimen (de cualquier ideología) tendrían un poderoso estímulo para continuar el cambio político por la vía institucional al ver resultados positivos de esta estrategia, reduciendo por tanto la tentación de los sectores duros de la oposición de recurrir a medios extrainstitucionales de lucha política.

C) Por otro lado, de no haber una reacción violenta por parte de los priístas ante este descalabro, muchos ciudadanos podrían percatarse de que el país puede sobrevivir sin sobresaltos demasiado fuertes ante una derrota del PRI, con lo cual el temor de que la democracia provoque una ruptura institucional podría ir disminuyendo hasta desaparecer.

D) Finalmente, este paso significaría un avance cualitativo en la dirección democrática, sin ser tan drástico como una pérdida de la presidencia de la República por parte del PRI (previsible en el futuro cercano); sería pues una especie de paso previo a ese posible desenlace. Los eventuales efectos disruptores de una alternancia se presentarían desde ahora, pero más reducidos (minimizando por ello los riesgos inherentes al momento en que se registre un cambio en la Presidencia).

Pero también, que con sus recursos políticos el PRI no haya podido remontar un resultado relativamente desfavorable, nos lleva a lo que se prevé como el 'fin de la liberalización política'. Según uno de los más destacados teóricos de este proceso, Adam Przeworski, "el mo- 


\section{JOSÉ ANTONIO CRESPO}

mento crucial en cualquier tránsito del autoritarismo a la democracia es el cruce del umbral más allá del cual nadie puede intervenir para revertir los resultados del proceso político formal". ${ }^{16}$ Eso es justamente lo que ha ocurrido en 1997; pese a los esfuerzos por parte del Gobierno y su partido por preservar la mayoría absoluta de la Cámara de Diputados, no pudo hacerse y el costo de hacerlo con actos ilícitos (comprobables y visibles) hubiera sido elevado para el propio Gobierno y para el futuro inmediato del país. Por lo mismo, podría decirse que la larga y exitosa estrategia liberalizadora, mediante la cual pudo preservarse la hegemonía priísta, llegó a su fin. Esto se debe a que la élite autoritaria ha perdido el control del proceso de cambio y por tanto la liberalización ha dado paso a la democratización, muy a pesar de la propia élite gobernante.

Desde luego, la mayoría absoluta del partido oficial en la Cámara Baja no es el único elemento esencial de la hegemonía partidista, pero sí uno de particular importancia. De modo que es posible tomar este descalabro electoral como un indicador de que la hegemonía priísta ha empezado a diluirse en íos hechos y no sólo como tendencia al futuro (la cual fue detectada desde hace muchos años). En esa medida, al PRI no le queda más remedio que ajustarse a la nueva dinámica de la democratización que ya no pudo impedir y convertirse en un partido competitivo, con capacidad propia para ganar el poder (que de cualquier forma ya no será hegemónico) o caer derrotado ante su parálisis y desaparecer, como ha ocurrido con otros partidos de origen monopólico (pues no parece probable que sin una reforma estructural de fondo el PRI pueda sobrevivir en la oposición).

Así pues, con los matices y reservas que desde el punto de vista teórico y político puedan hacerse, todo parece indicar que los comicios de 1997, tanto por las condiciones en las que fueron celebrados como por los resultados, han marcado con cierta claridad el fin del proyecto más prolongado y por tanto exitoso de liberalización política que hubiera registrado autoritarismo alguno en la época moderna.

${ }^{16}$ Democracy and the Market..., op. cit., p. 14. 